\title{
Influence of Imidazolium Ionic Liquids on Dehydrogenase Activity of Activated Sludge Microorganisms
}

\author{
Ewa Liwarska-Bizukojc
}

Received: 2 November 2010 / Accepted: 7 March 2011/Published online: 5 April 2011

(C) The Author(s) 2011. This article is published with open access at Springerlink.com

\begin{abstract}
Imidazolium salts are one of the most often used and investigated groups of ionic liquids (ILs). The research concerning their ecotoxicity comprised many test organisms representing different trophic levels; however, their impact on mixed cultures of microorganisms such as activated sludge has been hardly ever investigated. Thus, in this work, the effect of imidazolium ionic liquids on dehydrogenase activity of activated sludge was estimated. Three activated sludges of different properties and origin were tested. It occurred that 1-alkyl-3-methyl imidazolium bromides do not inhibit dehydrogenase activity of sludge, if the alkyl chain contains up to six carbon atoms. The values of IC50 for these ILs were above $100 \mathrm{mg} \mathrm{l}^{-1}$. At the same time, the inhibitory effect on dehydrogenase activity of activated sludge increases with the increase in chain length of the alkyl substituent. The degree of inhibition of dehydrogenase activity of sludge microorganisms is dependent on activated sludge properties.
\end{abstract}

Keywords Activated sludge $\cdot$ Dehydrogenase activity · Imidazolium · Inhibition · Ionic liquid

E. Liwarska-Bizukojc ( $\bowtie)$

Institute of Environmental Engineering,

Technical University of Lodz,

Al. Politechniki 6,

90-924 Lodz, Poland

e-mail: ewa.liwarska-bizukojc@p.lodz.pl

\section{Introduction}

Ionic liquids (ILs) possess a number of interesting properties like high polarity and ionic conductivity, and chemical and thermal stability. What is more important is that ILs are practically nonvolatile or induce negligible vapour pressure and cannot contribute to atmospheric pollution. Additionally, varying the cation and/or anion constituents alters the chemical and physical properties of an IL and makes it possible to design a solvent for a certain reaction. These properties of ILs caused, since the 1990s, their having become increasingly attractive as the potential green replacement for harmful volatile organic solvents in many industrial uses. Ionic liquids have been used in a variety of applications, like chemical analysis, extractions, sequestration of $\mathrm{CO}_{2}$ and electrolytes for batteries (Bernot et al. 2005; Pham et al. 2008).

Imidazolium-based ionic liquids belong to the most often used and thoroughly investigated ILs (Garcia et al. 2005; Jastorff et al. 2005; Docherty et al. 2007; Romero et al. 2008). Much work has focused on their ability to serve as the solvents for reactions and their potential as phase-transfer catalysts. The 1-alkyl-3methyl imidazolium salts are non-volatile, nonflammable, thermally stable and miscible with a wide range of inorganic and organic substances (Romero et al. 2008). The industrial production and utilisation along with the wide applicability of ILs may cause an increase of their presence in wastewater. Moreover, because of the high stability of ILs in water, these 
chemicals may become persistent pollutants in wastewater. It is believed that, particularly, wastewater from chemical production processes of ILs and landfill leachates will be subjected to wastewater treatment in future (Ranke et al. 2007). Although the values of ILs concentration in wastewater have been not published so far (Pham et al. 2010), the research concerning the recovery of ILs from wastewater as well as the treatment of wastewater containing ILs have been being performed for several years (Ranke et al. 2007; Fernández et al. 2008; Stolte et al. 2008). In these studies, the individual selected concentration of ILs, i.e. $40 \mathrm{mg} \mathrm{l}^{-1}$ (Stolte et al. 2008) or wide range of ILs concentrations up to $1 \mathrm{M}$ were tested (Fernández et al. 2008). Pham et al. (2010), concluding their review, emphasized the necessity of the initial guidelines formulation for the treatment of waste streams containing ILs by using the existing wastewater treatment plants (WWTPs). For these reasons, it is a priority to determine biological activity of ILs including their effect on biological wastewater treatment processes.

The research, which has been performed so far, with regard to the biological activity of imidazoliumbased ILs focused mainly on two subjects: biodegradability and toxicity of ILs towards aquatic organisms. Biodegradability of ILs was estimated with the use of normalised OECD tests (Gathergood et al. 2004; Docherty et al. 2007; Gathergood et al. 2006). Docherty et al. (2007) showed that hexyl and octyl substituted imidazolium-based ILs were only partially mineralised, while pyridinium-based ILs could be fully mineralised. Garcia et al. (2005) found that dialkylimidazolium ILs showed the negligible biodegradability; however, the incorporation of an ester in the side chain of the imidazolium cation increased their biodegradability. Ecotoxicity of imidazolium ILs depends on their chemical structure and organisms used in the tests (Pham et al. 2010). One of the main conclusions, which emerged from the ecotoxicity research, is that the inhibitory potential of an ionic liquid increases with the increase in chain length of the alkyl substituent. Ecotoxicity tests examining the acute and chronic effect of ILs on the aquatic environment comprised the following organisms: algae (Scenedesmus sp.), crustaceans (Daphnia magna), molluscs (Physa acuta), fish (Danio rerio, Pimaphales promelas) and plants (Lemma minor; Bernot et al. 2005; Pretti et al. 2006; Pham et al. 2008; Ventura et al.
2010). Out of prokaryotic organisms, the marine luminescent bacteria Vibrio fischeri (formerly Photobacterium phosphoreum) were usually used in the ecotoxicity tests (Matsumoto et al. 2004; Docherty and Kulpa 2005; Garcia et al. 2005; Romero et al. 2008). Docherty and Kulpa (2005) also investigated the antimicrobial activity of imidazolium and pyridinium ILs to a diverse set of microorganisms including Grampositive and Gram-negative rods and Gram-positive cocci. All these studies were performed with the use of the pure cultures of microorganisms. At the same time, the effect of ILs on such bacterial aggregates as activated sludge or biofilm has been hardly ever investigated until now. This gap should be filled because mixed cultures are widespread used in wastewater treatment processes (Bitton 2005).

In this study, the effect of ILs on dehydrogenase activity of activated sludge was investigated. Dehydrogenases are oxidoreductases, which participate in the transport of electrons from organic substrates to electron acceptors. Their activity is regarded as a universal indicator of bacterial metabolic activity (Singh et al. 1994). Due to the fact that the physiological state of activated sludge may vary and depends on many factors including technological parameters, e.g. sludge age, sludge concentration, sludge loading rate and temperature (Henze et al. 2002), the tests were performed with different activated sludges taken from three wastewater treatment plants of different activated sludge systems. The main aim of this work is to express quantitatively the effect of imidazolium-based ionic liquids on dehydrogenase activity of activated sludge microorganisms. Hence, the reliable values (or ranges) of inhibition concentrations are going to be estimated.

\section{Materials and Methods}

\subsection{Ionic Liquids}

The dehydrogenase activity tests were performed for three imidazolium ionic liquids with the increasing length of alkyl chain substituents: 1-ethyl-3-methylimidazolium bromide, 1-hexyl-3-methylimidazolium bromide and 1-decyl-3-methylimidazolium bromide. The short description of the ionic liquids including their chemical composition and molecular weight is presented in Table 1. All imidazolium-based ionic 
Table 1 Chemical names and codes, molecular weights, structural formulae and purity of the studied ionic liquids

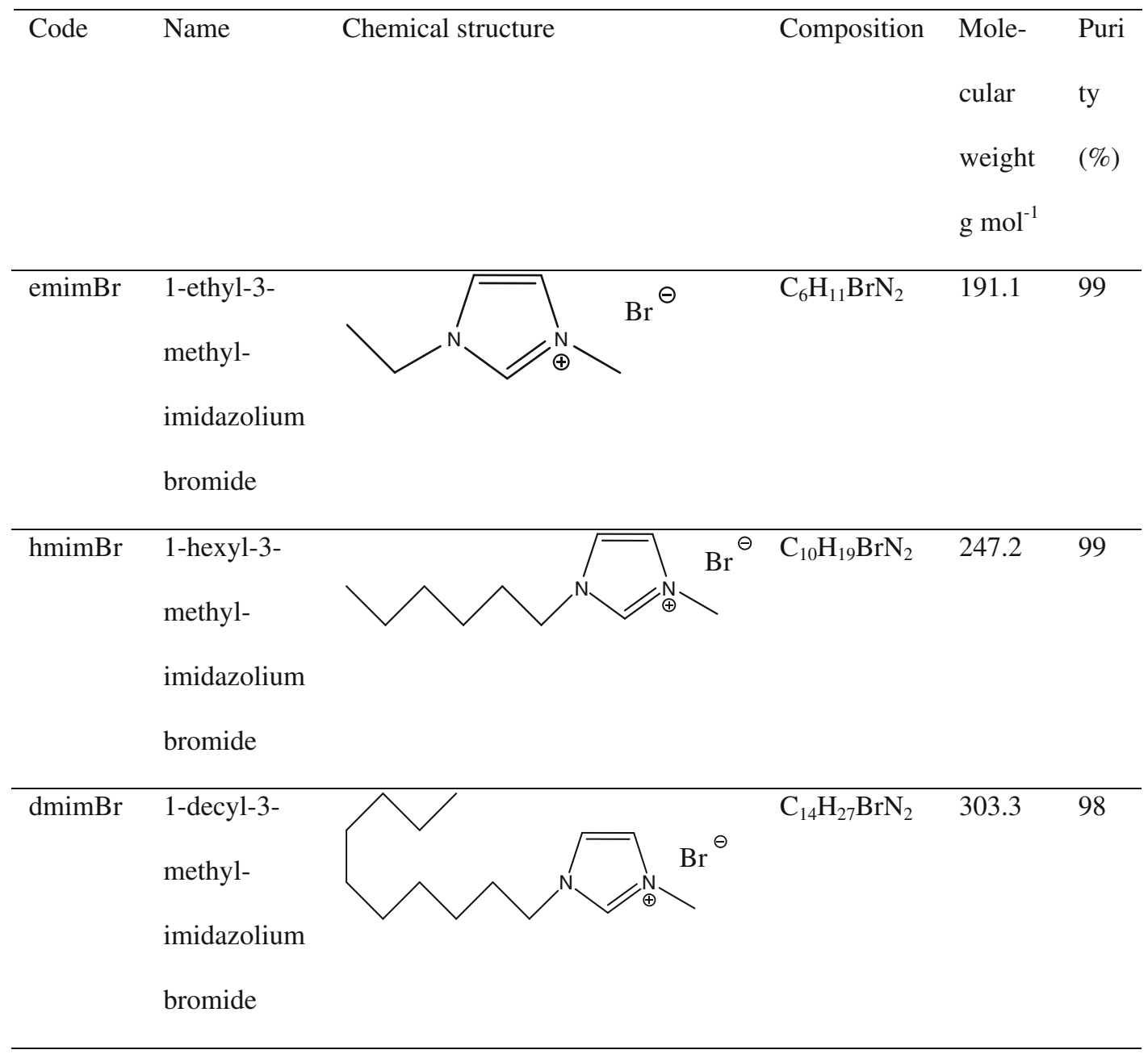

liquids used in this work were purchased from Ionic Liquids Technologies GmbH (Denzlingen, Germany).

Additionally, the dehydrogenase activity tests were made for a well-known organic solvent methanol to enable the comparison between ILs and the solvent used so far. The dehydrogenase activity tests were performed for each tested chemical individually.

\subsection{Dehydrogenase Activity Test}

Dehydrogenase activity was determined according to Miksch (1985) with the use of 2,3,5-triphenyltetrazolium chloride (TTC). Under mild reducing conditions, the colourless TTC is converted into coloured 1,3,5triphenyloterazolium formazan (TF). The test consists of the following stages: (1) addition of the reagents to the activated sludge in the proper order: $0.2 \%$ solution of sodium sulphite $\left(\mathrm{Na}_{2} \mathrm{SO}_{3}\right)$, distilled water (control sample) or the proper solution of the tested chemical (ionic liquid or methanol), and finally $1 \%$ solution of TTC; (2) incubation in the dark at room temperature $21^{\circ} \mathrm{C} \pm 0.5$; (3) sludge separation; (4) stopping the reaction by the addition of pure $100 \%$ methanol; and (5) measurement of absorbance at $485 \mathrm{~nm}$. TTC solutions in the range from $0.2 \%$ to $2 \%$ were tested in order to optimise the concentration of this reagent in the dehydrogenase tests. It occurred that $1 \%$ solution of TTC was optimal for the activated sludges studied. The incubation time equal to $1 \mathrm{~h}$ was assumed in all tests. The incubation time started in the moment of TTC addition and ended when the reaction was stopped by the addition of pure methanol. Each 
control sample was analysed in six replications, whereas the test sample in triplicate for each concentration studied.

The results obtained for each concentration were averaged, and then the degree of inhibition $\left(I_{\mathrm{DHG}}\right)$ was calculated according to the following equation:

$I_{\mathrm{DHG}}=\frac{A_{c}-A_{t}}{A_{c}} \cdot 100(\%)$

where $A_{\mathrm{c}}$ is the mean value of dehydrogenase activity of activated sludge not exposed to the tested chemicals (control sample) and $A_{\mathrm{t}}$ is the mean value of dehydrogenase activity of activated sludge exposed to the tested chemicals (test sample).

On the basis of variation of $I_{\mathrm{DHG}}$ versus concentration of the tested chemical, the values of inhibition concentration IC50 were estimated for the ionic liquids and methanol. The correlation between $I_{\mathrm{DHG}}$ and IL concentration $\left(c_{\mathrm{IL}}\right)$ was approximated with the use of hyperbolic function expressed by the following equation:

$I_{\mathrm{DHG}}=\frac{P 1 \cdot c_{\mathrm{IL}}}{P 2+c_{\mathrm{IL}}}$

where $P 1$ is the parameter expressing the maximal degree of inhibition $\left(I_{\mathrm{DHG}, \max }\right)$ and $P 2$ is the parameter expressing the concentration, at which the degree of inhibition is equal to half of the maximal degree of inhibition. The value of IC50 was estimated upon the results of this approximation, i.e. using the parameters $P 1$ and $P 2$ and substituting $I_{\mathrm{DHG}}$ equal to $50 \%$.

The non-linear approximations of Eq. 2 were performed individually for each ionic liquid and sludge with the help of least squares method. The approximation made for the ionic liquid $\mathrm{dmimBr}$ and sludge AL is shown in Fig. 1 as an example.

\subsection{Other Analytical Methods}

Biochemical Oxygen Demand, total solids, volatile solids, total suspended solids (TSS), volatile suspended solids (VSS) and sludge volume index (SVI) were measured according to the standard methods (APHA-AWWA-WPCF 1995).

Activated sludge taken from the aeration chamber of WWTP was subjected to microscopic observations. The vital unstained slides of activated sludge were prepared. The morphological parameters of the flocs, i.e. mean projected area, perimeter, mean diameter (d) and circularity index, were measured with the help of digital image analysis software Micro Image 4.0 (Media Cybernetics for Olympus). Details of image analysis procedures for activated sludge flocs were presented elsewhere (Liwarska-Bizukojc and Bizukojc 2006). The quantity of filamentous microorganisms was estimated in the agreement with the classification presented by Eikelboom and van Buijsen (1992).
Fig. 1 Determination of the inhibition concentration IC50 for the ionic liquid dmimBr and sludge AL

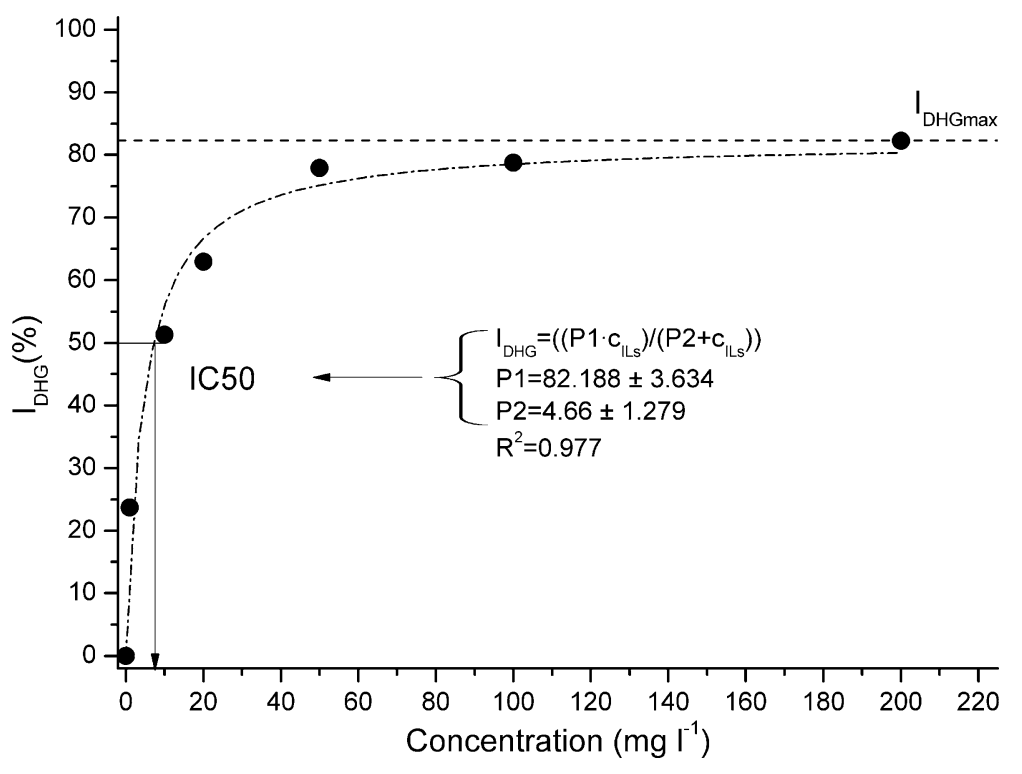




\subsection{Characteristics of Activated Sludges}

Activated sludges taken from the aeration chambers of different WWTPs in Poland were used in the dehydrogenase tests. They came from WWTPs of different activated sludge systems and different flow capacity, which varied from $5,000 \mathrm{~m}^{3} \mathrm{~d}^{-1}$ to $100,000 \mathrm{~m}^{3} \mathrm{~d}^{-1}$ (Table 2). These were the WWTP in Lodz (L), the WWTP in Zgierz (Z) and the WWTP in Aleksandrow Lodzki (AL). All WWTPs treated domestic wastewater; however, in one of them, i.e. the WWTP Zgierz the contribution of industrial wastewater is significant and varies in the range from $10 \%$ to $15 \%$. Sludge samples were taken three times from each WWTP studied every 4 weeks from September to December 2009. At the same time, the information about the operation of the WWTPs studied in these periods of time was collected. Characteristics of the activated sludges used in the dehydrogenase tests and the WWTPs studied are presented in Table 2. The sludges used in the tests differed from each other with regard to sludge loading rate $\left(L_{\mathrm{X}}\right)$, sludge retention time (SRT) and settling properties. The content of solid particles including VSS was at similar level (Table 2). Dehydrogenase activity of two tested sludges (L and AL) was on average at the same level of $6 \mathrm{mg} \mathrm{TF} \mathrm{g} \mathrm{TSS}^{-1} \mathrm{~h}^{-1}$ (Table 2), while the activity of sludge $\mathrm{Z}$ was about $30 \%$ lower. Two of the sludges, i.e. $\mathrm{L}$ and $\mathrm{Z}$, consisted of flocs of similar morphological parameters with regard to flocs size, whereas sludge AL had very small flocs, whose mean diameter (d) was usually below $60 \mu \mathrm{m}$. Small flocs and the high number of filamentous bacteria deteriorated settling properties of sludge AL and caused the formation of sludge blanket. Thus, the calculation of SVI was less reliable for this sludge.

\section{Results and Discussion}

The dehydrogenase activity test enables easy and fast determination of the respirometric activity of biomass because almost all metabolic pathways of the consumed substrates meet together in the respiratory chain. The determination of dehydrogenase activity is also regarded as the useful method for assessing sludge activity as well as toxicity of various chemicals or wastewater towards sludge (Singh et al. 1994; Ren 2004). The results of the dehydrogenase activity tests

Table 2 Characteristics of the activated sludges and activated sludge systems of the WWTPs studied

\begin{tabular}{|c|c|c|c|}
\hline Characteristic feature & Sludge L (WWTP Lodz) & Sludge Z (WWTP Zgierz) & $\begin{array}{l}\text { Sludge AL (WWTP } \\
\text { Aleksandrow Lodzki) }\end{array}$ \\
\hline $\begin{array}{l}\text { Type of activated } \\
\text { sludge system }\end{array}$ & $\begin{array}{l}\text { Modified UCT } \\
\text { (three stages) }\end{array}$ & Phoredox (three stages) & Bardenpho (five stages) \\
\hline $\begin{array}{l}\text { Average daily flow } \\
\text { rate }\left(\mathrm{m}^{3} \mathrm{~d}^{-1}\right)\end{array}$ & 100,000 & 11,500 & 5,000 \\
\hline $\begin{array}{l}\text { Average sludge } \\
\text { loading rate } \\
\left(\mathrm{g} \mathrm{BOD} \mathrm{g} \mathrm{TS}^{-1} \mathrm{~d}^{-1}\right)\end{array}$ & 0.07 & 0.11 & 0.12 \\
\hline SRT (d) & $10-12$ & $19-22$ & $12-14$ \\
\hline TSS $\left(\mathrm{g} \mathrm{kg}^{-1}\right)$ & $2.9-4.7$ & $3.2-3.9$ & $2.4-4.0$ \\
\hline VSS $\left(\mathrm{g} \mathrm{kg}^{-1}\right)$ & $1.9-3.8$ & $2.1-2.8$ & $1.9-3.4$ \\
\hline SVI (ml g TSS $\left.{ }^{-1}\right)$ & $134-190$ & $41-49$ & $\begin{array}{l}115-130+ \\
\text { sludge blanket }\end{array}$ \\
\hline Mean projected area $\left(\mu \mathrm{m}^{2}\right)$ & $23380 \pm 2900$ & $21410 \pm 1750$ & $4880 \pm 535$ \\
\hline $\begin{array}{l}\text { The mean diameter of } \\
\text { flocs }(\mu \mathrm{m})\end{array}$ & $138 \pm 13$ & $132 \pm 9$ & $59 \pm 7$ \\
\hline Filamentous microorganisms & $\begin{array}{l}\text { Mediocre number, } \\
\text { category } 2^{\mathrm{a}}\end{array}$ & Appear rarely, category $1^{\mathrm{a}}$ & High number, category $3^{a}$ \\
\hline $\begin{array}{l}\text { Mean dehydrogenase activity } \\
\left(\mathrm{mg} \text { TF } \mathrm{g} \mathrm{TSS}^{-1} \mathrm{~h}^{-1}\right)\end{array}$ & 5.85 & 4.29 & 6.12 \\
\hline
\end{tabular}

${ }^{\text {a }}$ Classification according to Eikelboom and van Buijsen (1992) 
performed in order to estimate the effect of imidazolium-based ionic liquids on activated sludge are presented in Table 3. It occurred that the ionic liquid with the shortest alkyl side chain length, i.e. emimBr, was generally non-toxic towards each activated sludge used up to the concentration equal to $1,000 \mathrm{mg}^{-1}$. The similar situation took place with regard to methanol (Table 3). The concentration of $1,000 \mathrm{mg} \mathrm{l}^{-1}$ was set as a threshold, above which there was no need to test toxicity. It is due to the fact that such high concentrations (above $1,000 \mathrm{mg}^{-1}$ ) of chemicals have been hardly ever met in wastewater. The inhibitory effect of hmimBr expressed as IC50 varied from 336.5 to $650 \mathrm{mg}^{-1}$, dependent on the activated sludge used. The values of IC50 estimated for dmimBr were in the range between 7.2 and $55.6 \mathrm{mg} \mathrm{l}^{-1}$ and also depended on the activated sludge applied. Analysing the results presented in Table 3, three main issues should be noticed and discussed.

First of all, the inhibitory potential of the tested imidazolium ionic liquids increased with the increase in chain length of the alkyl substituent. In spite of the fact that similar observations have been made so far, they did not concern activated sludge microorganisms.

Pernak et al. (2003) observed a trend of increasing toxicity with the increase in the alkyl chain length substituent in the imidazolium salts to several pure cultures of bacteria and fungi. Docherty and Kulpa (2005) investigated the toxicity of three imidazolium ILs towards $V$. fischeri using Microtox method. Additionally, the antimicrobial activity of these ILs to a diverse set of microorganisms including Gram- positive and Gram-negative rods and Gram-positive cocci was estimated. It was observed that the toxicity towards $V$. fischeri increased with increasing hydrophobicity of the 1-alkyl-3-methyl imidazolium bromides (Docherty and Kulpa 2005). All ILs had the antimicrobial activity to pure cultures of tested microorganisms. However, in case of 1-butyl-3-methyl imidazolium bromide, this activity was lower than of ILs with longer alkyl chain. Romero et al. (2008) tested the toxicity of several ILs consisting of the imidazolium cation with two alkyl substituents and diverse anions $\left(\mathrm{Cl}^{-}, \mathrm{PF}_{6}^{-}, \mathrm{XSO}_{4}{ }^{-}\right)$towards $V$. fischeri. It occurred that the influence of the anion on the value of EC50 was insignificant, whereas the increase of alkyl chain resulted in a remarkable increase of the acute toxicity of the imidazolium ILs tested.

The results obtained here supplemented the aforementioned studies with respect to the mixed cultures of microorganisms. This work showed that the trend of increasing toxicity with the increase of alkyl chain length in the 1-alkyl-3-methyl imidazolium bromides occurred not only in the pure cultures but also in the mixed populations of microorganisms like activated sludge. According to the classification of chemical substances toxicity (Commission Directive 2009), two ILs examined, i.e. emimBr and $\mathrm{hmimBr}$, are not toxic towards microorganisms of activated sludge, whereas the ionic liquid dmimBr can be regarded as harmful. It indicates that the 1-alkyl-3-methyl imidazolium bromides of the length of alkyl chain from one to six carbon atoms should not deteriorate activated sludge system and, as a consequence, biological wastewater
Table 3 Comparison of toxicity of the tested imidazolium-based ionic liquids to activated sludge taken from different WWTPs

\begin{tabular}{llcllc}
\hline Substance & Sludge & $I_{\text {DHG,max }}(\%)$ & $P 2\left(\mathrm{mg} \mathrm{l}^{-1}\right)$ & $R^{2}$ & IC50 $\left(\mathrm{mg} \mathrm{l}^{-1}\right)$ \\
\hline emimBr & L & - & $>1,000$ & N/D & $>1,000$ \\
& Z & - & $>1,000$ & N/D & $>1,000$ \\
& AL & $61.2 \pm 5.9$ & $988 \pm 191$ & 0.916 & $>1,000$ \\
hmimBr & L & $76 \pm 22.2$ & $338 \pm 235$ & 0.905 & $650 \pm 452$ \\
& Z & $98 \pm 3.7$ & $533 \pm 75$ & 0.960 & $555 \pm 78$ \\
& AL & $63 \pm 4.3$ & $87.5 \pm 25.3$ & 0.983 & $336 \pm 97$ \\
dmimBr & L & $93 \pm 3.4$ & $47.8 \pm 8.1$ & 0.989 & $55.6 \pm 9.5$ \\
& Z & $80 \pm 5.1$ & $20.4 \pm 6.6$ & 0.969 & $34 \pm 11$ \\
& AL & $82.2 \pm 3.6$ & $4.66 \pm 1.28$ & 0.977 & $7.2 \pm 2$ \\
Methanol & L & - & $>1,000$ & N/D & $>1,000$ \\
& Z & & $>1,000$ & N/D & $>1,000$ \\
& AL & & $>1,000$ & N/D & $>1,000$ \\
\hline
\end{tabular}


treatment processes with regard to the biochemical activity of microorganisms.

The second important issue resulting from the performed experiments concerned the comparison between the toxicity of the tested ILs and toxicity of the commonly used solvent, i.e. methanol. This study demonstrated that the 1-alkyl-3-methyl imidazolium bromides were more toxic than methanol, if the alkyl chain consisted of at least six carbon atoms. The results of tests with $V$. fischeri made by Docherty and Kulpa (2005) indicated that the toxicity of the imidazolium based ILs exceeded the toxicity of methanol started with the alkyl chain length of four carbon atoms, i.e. for 1-butyl-3-methyl imidazolium bromide. It means that toxicity of 1-alkyl-3-methyl imidazolium bromides with short alkyl chains (from one to three carbon atoms) is comparable to the toxicity of methanol.

The last issue, which requires discussion in the light of the obtained results, is connected with the response of activated sludge to ILs exposure. This response differed dependent on the activated sludge used. Activated sludge was taken from three different WWTPs. The description of activated sludges used in the dehydrogenase activity tests was presented in section 2.4. The initial dehydrogenase activity of the activated sludges determined under the same analytical conditions was at the similar level from 4.29 to $6.12 \mathrm{mg} \mathrm{TF} \mathrm{g} \mathrm{TSS}^{-1} \mathrm{~h}^{-1}$ (Table 2). At the same time, the response of each activated sludge to IL exposure was not the same but differed significantly. Sludge AL was inhibited to a highest extent by the imidazolium-based ILs examined despite the fact that this sludge had the highest initial dehydrogenase activity (compare Tables 2 and 3). At the same time, sludge $L$ and $Z$, whose initial dehydrogenase activity was lower than sludge $\mathrm{AL}$, occurred to be significantly more resistant to ILs exposure. The values of IC50 estimated for each of ILs tested were higher for sludge $\mathrm{L}$ and $\mathrm{Z}$ in comparison to sludge AL (Table 3). In case of two ILs tested, i.e. hmimBr and $\mathrm{dmimBr}$, the values of IC50 estimated for sludge L and Z were higher even by one order of magnitude in relation to sludge AL. The third out of ionic liquids tested, i.e. emimBr, did not inhibit the dehydrogenase activity of the sludges tested in the range of concentrations from 0.1 to $1000 \mathrm{mg} \mathrm{l}^{-1}$. However, taking all results obtained for emimBr into account, the maximal degree of inhibition was estimated only for sludge AL (Table 3). It indicated that ionic liquid emimBr inhibited this sludge stronger than the other two sludges. The above-mentioned observations mean that the high initial dehydrogenase activity of sludge does not protect it against such xenobiotics as imidazoliumbased ILs. In this situation, the question arises if
Fig. 2 Influence of activated sludge properties on the inhibitory effect of the ionic liquids tested

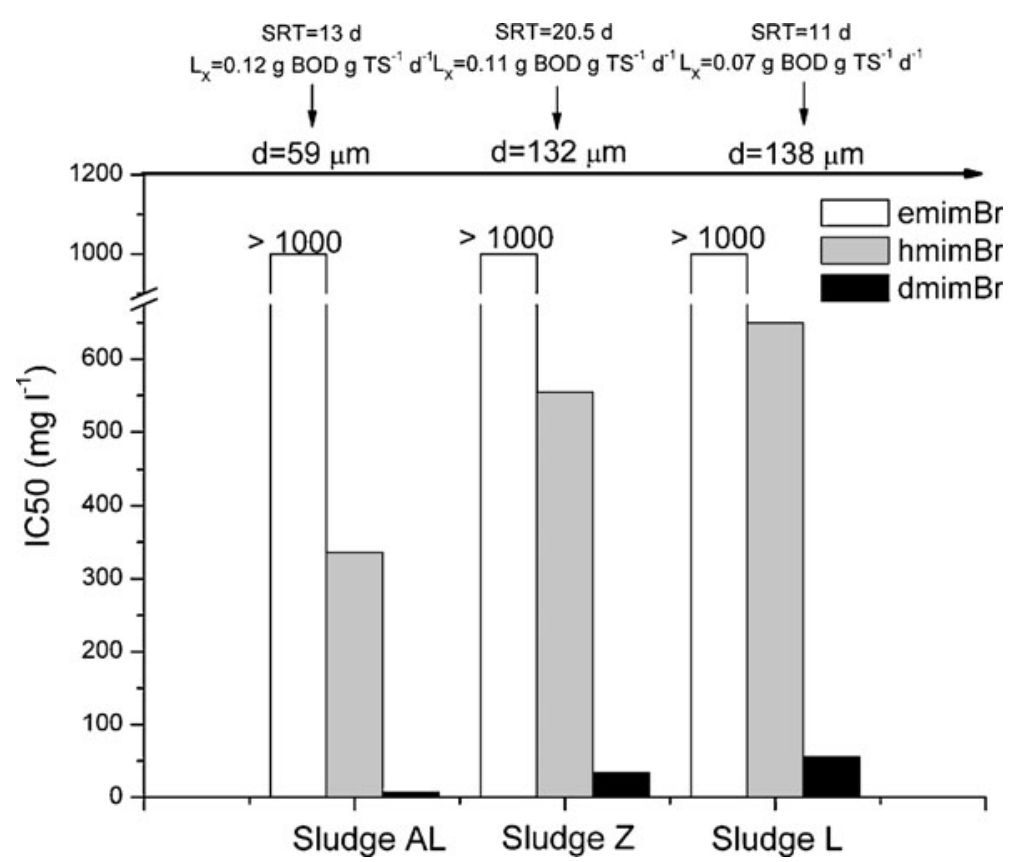


there is any correlation between other activated sludge properties and inhibitory effect of ionic liquids on biochemical activity of sludge.

Analysing the influence of the operational parameters, i.e. SRT and sludge loading rate $\left(L_{X}\right)$, on the inhibitory effect of ILs towards activated sludge microorganisms, it is difficult to find any unequivocal correlation. However, it should be noticed that sludge AL was higher loaded than the other two sludges ( $\mathrm{L}$ and $\mathrm{Z}$ ), and its age was relatively low (12-14 d). Sludge L had also low age (10-12 d) but sludge loading rate in the WWTP Lodz was the lowest compared with the other two WWTPs studied. At the same time, the sludge loading rate for sludge $Z$ was only slightly (about 10\%) lower than for sludge AL; however, this sludge was "the oldest" out of the three sludges used (Table 2). The age of sludge $Z$ was in the range from 19 to $22 \mathrm{~d}$. It may be claimed that the sludge, which has low sludge age and concurrently is strongly loaded by organic matter, is more susceptible to the action of imidazolium-based ILs (Fig. 2).

Finally, the correlation between the morphology of activated sludge flocs and response of sludge to the imidazolium-based ILs exposure was analysed. Ideally, sludge flocs should be firm, spherical and of medium size (Eikelboom and van Buijsen 1992; Bitton 2005). It occurred that sludge AL, which consisted of small flocs (mean diameter below $60 \mu \mathrm{m}$ ) and high number of filamentous organisms was stronger affected by the ILs examined than the other two sludges (Table 2, Fig. 2). Due to small flocs and high number of filamentous organisms, sludge AL had also poor settleability and it was difficult to calculate the sludge volume index for it. Flocs of sludge $\mathrm{L}$ and $\mathrm{Z}$ can be classified as medium size according to the classification presented by Eikelboom and van Buijsen (1992) because their mean diameter was in the range from 100 to $300 \mu \mathrm{m}$. Also, the number of filamentous organisms was lower in these sludges than it was observed for sludge AL. The sludges $\mathrm{L}$ and $\mathrm{Z}$ were more resistant to the action of the ILs tested than sludge AL (Fig. 2).

The obtained results do not allow for the conclusion that the sludge consisting of small flocs is more susceptible to the impact of imidazoliumbased ILs. However, the knowledge about sludge flocs structure and morphology enables predicting, whether activated sludge may be stronger or weaker affected by ILs.

\section{Conclusions}

Imidazolium-based ILs containing up to six carbon atoms in the alkyl chain do not inhibit biochemical activity of sludge. The inhibitory effect on dehydrogenase activity of activated sludge microorganisms increases with the increase in chain length of the alkyl substituent. The ionic liquid 1-decyl-3-methyl imidazolium bromide can be regarded as harmful towards activated sludge biomass.

The degree of inhibition of dehydrogenase activity of sludge microorganisms is dependent on activated sludge properties. Activated sludge to be used for the treatment of wastewater containing imidazoliumbased ILs should have appropriate features, i.e. sludge age, sludge loading rate, the ratio between filamentous and floc-forming bacteria. In the future, the comprehensive studies concerning the influence of ILs on activated sludge system, including flocs morphology and sludge settleability, are suggested.

Acknowledgements The author acknowledges financial support of the Dean of Faculty of Civil Engineering, Architecture and Environmental Engineering, Technical University of Lodz, Poland.

Open Access This article is distributed under the terms of the Creative Commons Attribution Noncommercial License which permits any noncommercial use, distribution, and reproduction in any medium, provided the original author(s) and source are credited.

\section{References}

APHA-AWWA-WPCF. (1995). Standard methods for the examination of water and wastewater (19th ed.). Washington: APHA-AWWA-WPCF.

Bernot, R. J., Brueseke, M. A., Evans-White, M. A., \& Lamberti, G. A. (2005). Acute and chronic toxicity of imidazolium-based ionic liquids on Daphnia magna. Environmental Toxicology and Chemistry, 24(1), 87-92.

Bitton, G. (2005). Wastewater microbiology (3rd ed.). Hoboken: John Wiley \& Sons Inc.

Commission Directive 2009/2/EC of 15 January 1992 amending for the purpose of its adaptation to technical progress, for the 31-st time Directive 67/548/EEC on the approximation of the laws, regulations and administrative provisions relating to the classification, packaging and labelling of dangerous substances, Official Journal of the European Communities, 11/6, 2009.

Docherty, K. M., Dixon, J. K., \& Kulpa Jr, Ch F. (2007). Biodegradability of imidazolium and pyridinium ionic 
liquids by an activated sludge microbial community. Biodegradation, 18, 481-493.

Docherty, K. M., \& Kulpa Jr, Ch F. (2005). Toxicity and antimicrobial activity of imidazolium and pyridinium ionic liquids. Green Chemistry, 7, 185-189.

Eikelboom, D. H., \& van Buijsen, H. J. J. (1992). Handbook for microbiological investigation of sludge (Handbuch für die mikrobiologische Schlammuntersuchung). Munich: F. Hirthammer Verlag GmbH.

Fernández, J. F., Waterkamp, D., \& Thöming, J. (2008). Recovery of ionic liquids from wastewater: Aggregation control for intensified membrane filtration. Desalination, 224, 52-56.

Garcia, M. T., Gathergood, N., \& Scammells, P. J. (2005). Biodegradable ionic liquids. Part II. Effect of the anion and toxicology. Green Chemistry, 7, 9-14.

Gathergood, N., Garcia, M. T., \& Scammells, P. J. (2004). Biodegradable ionic liquids. Part I. Concept, preliminary targets and evolution. Green Chemistry, 6, 166-175.

Gathergood, N., Scammells, P. J., \& Garcia, M. T. (2006). Biodegradable ionic liquids. Part III. The first readily biodegradable ionic liquids. Green Chemistry, 8, 156-160.

Henze, M., Harremoës, P., Jansen, J., \& Arvin, E. (2002). Wastewater treatment. Biological and chemical processes. Berlin Heidelberg: Springer.

Jastorff, B., Mölter, K., Behrend, P., Bottin-Weber, U., Filser, J., Heimers, A., et al. (2005). Progress in evaluation of risk potential of ionic liquids-basis for an eco-design of sustainable products. Green Chemistry, 7, 362-372.

Liwarska-Bizukojc, E., \& Bizukojc, M. (2006). Effect of selected anionic surfactants on activated sludge flocs. Enz Microb Technol, 39, 660-668.

Matsumoto, M., Mochiduki, K., \& Kondo, K. (2004). Toxicity of ionic liquids and organic solvents to lactic acid-producing bacteria. Journal of Bioscience and Bioengineering, 98, 344-347.

Miksch, K. (1985). Selection of the optimum methodology to determine the actvity of activated sludge with the help of
TTC tests (Auswahl einer optimalen Methodik für die Aktivitätsbestimmung des Belebtschlammes mit Hilfe des TTC-Testes). Vom Wasser, 64, 187-198.

Pernak, J., Sobaszkiewicz, K., \& Mirska, I. (2003). Anti-microbial activities of ionic liquids. Green Chemistry, 5, 52-56.

Pham, T. P. T., Cho, Ch W, Vijayaraghavan, K., Min, J., \& Yun, Y. S. (2008). Effect of imidazolium-based ionic liquids on the photosynthetic activity and growth rate of Selenastrum capricornutum. Environmental Toxicology and Chemistry, 27(7), 1583-1589.

Pham, T. P. T., Cho, Ch W, \& Yun, Y. S. (2010). Environmental fate and toxicity of ionic liquids: A review. Water Research, 34, 353-372.

Pretti, C., Chiappe, C., Pieraccini, D., Gregori, M., Abramo, F., Monni, G., et al. (2006). Acute toxicity of ionic liquids to the zebrafish (Danio rerio). Green Chemistry, 8, 238-240.

Ranke, J., Stolte, S., Störmann, R., Arning, J., \& Jastorff, B. (2007). Design of sustainable chemical products-The example of ionic liquids. Chemical Reviews, 107, 2183-2206.

Ren, S. (2004). Assessing wastewater toxicity to activated sludge: Recent research and developments. Environment International, 30, 1151-1164.

Romero, A., Santos, A., Tojo, J., \& Rodriguez, A. (2008). Toxicity and biodegradability of imidazolium liquids. Journal of Hazardous Materials, 151, 268-273.

Singh, A., Kuhad, R. C., Sahai, V., \& Ghosh, P. (1994). Evaluation of biomass. Advances in Biochemical Engineering/Biotechnology, 51, 42-70.

Stolte, S., Abdulkarim, S., Arning, J., Blomeyer-Nienstedt, A. K., Bottin-Weber, U., Matzke, M., et al. (2008). Primary biodegradation of ionic liquid cations, identification of degradation products of 1-methyl-3-octylimidazolium chloride and electrochemical wastewater treatment of poorly biodegradable compounds. Green Chemistry, 10, 214-224.

Ventura, S. P. M., Goncalves, A. M. M., Goncalves, F., \& Coutinho, J. A. P. (2010). Assessing the toxicity on $[\mathrm{C} 3 \mathrm{mim}][\mathrm{Tf} 2 \mathrm{~N}]$ to aquatic organisms of different trophic levels. Aquatic Toxicology, 96, 290-297. 